\title{
The single-use fixed bed bioreactors in viral vector production
}

\author{
Hanna Lesch ${ }^{1}$, Piia Valonen ${ }^{2}$, and Minna Karhinen ${ }^{2}$ \\ ${ }^{1}$ Kuopio Center for Gene and Cell Therapy \\ ${ }^{2}$ Finvector
}

May 18, 2020

\begin{abstract}
The accelerating development of gene therapy from research towards clinical trials and beyond has elevated the demand for practical viral vector manufacturing solutions. The use of disposable upstream technology is gaining traction in clinical manufacturing. The world's first disposable, fully integrated, high-cell density fixed-bed bioreactor was launched approximately one decade ago. By now, the iCELLis fixed-bed technology has obtained the broadest customer base. This system is available in small scale but also provides the largest GMP compliant commercial system. However, there are several alternative technologies, which have been widely used for the manufacturing of different viral vectors, allowing for complementation within the market. This article will review virus production using the latest disposable fixed-bed bioreactors, present highlights of an interview with the inventor of these bioreactors, and share some user experience. It is predicted that single-use fixed-bed bioreactors will receive even more attention in the field of viral vector manufacturing and commercialization, especially with high virus yields.
\end{abstract}

\section{Hosted file}

The use of fixed bed bioreactor in virus production - Final.docx available at https: //authorea.com/users/323200/articles/452151-the-single-use-fixed-bed-bioreactors-inviral-vector-production 
a

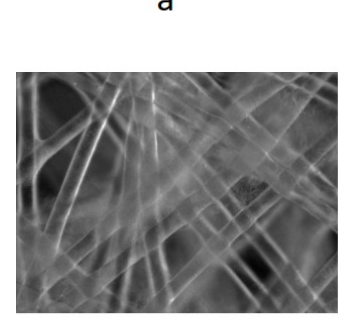

b

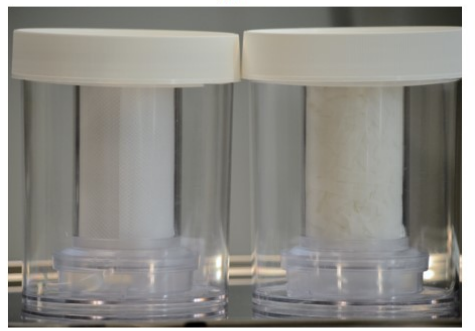

d
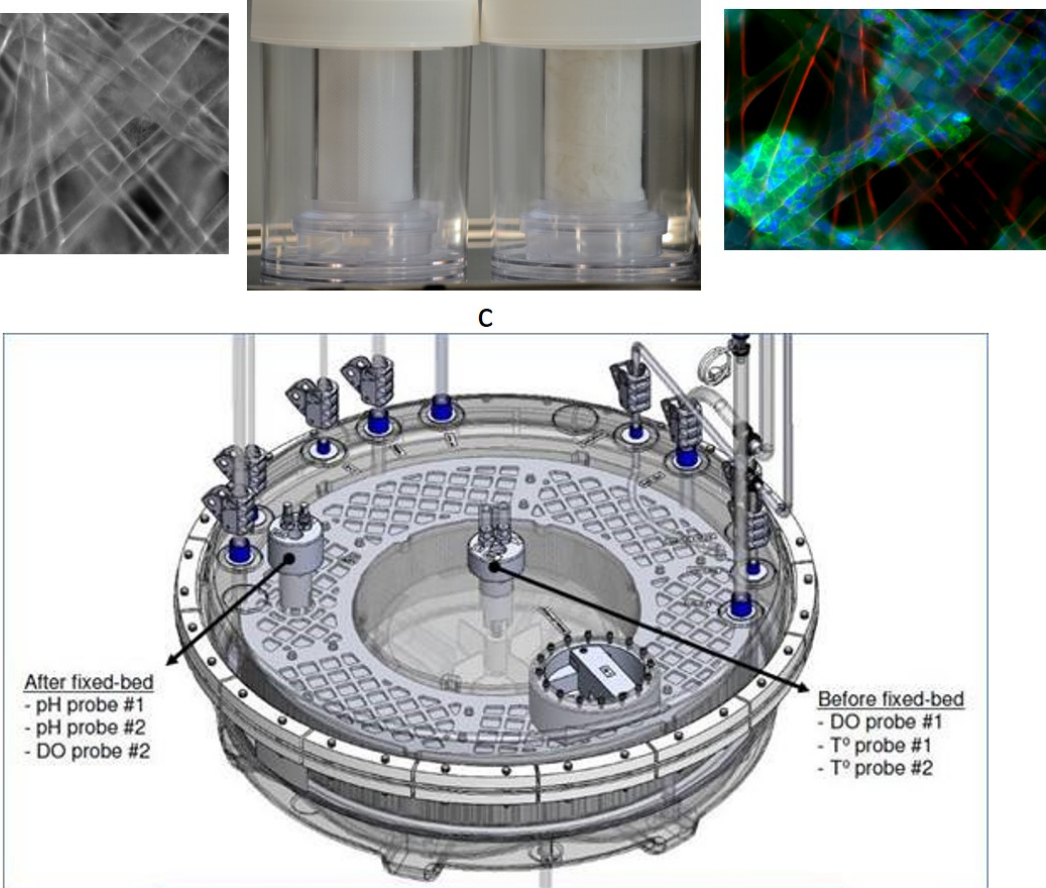

A. Recirculation of the medium

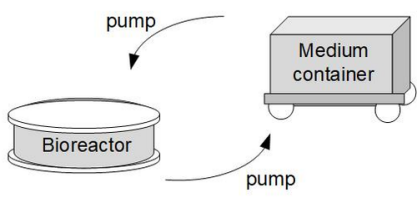

B. Perfusion of the medium

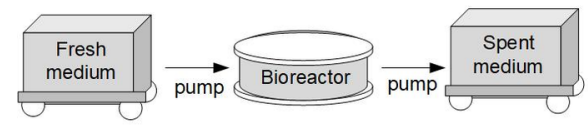

c.

\section{Viral vector} manufacturing

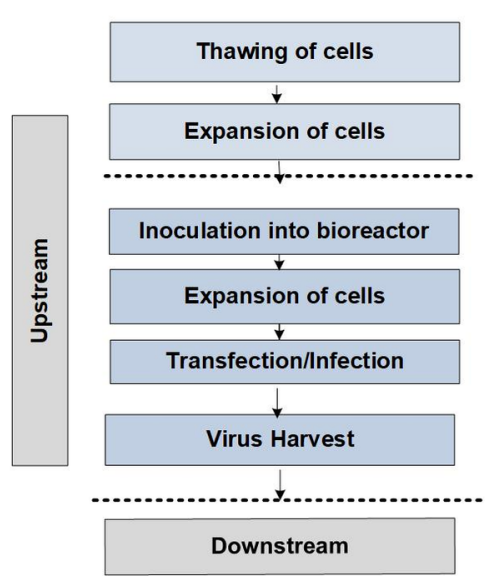




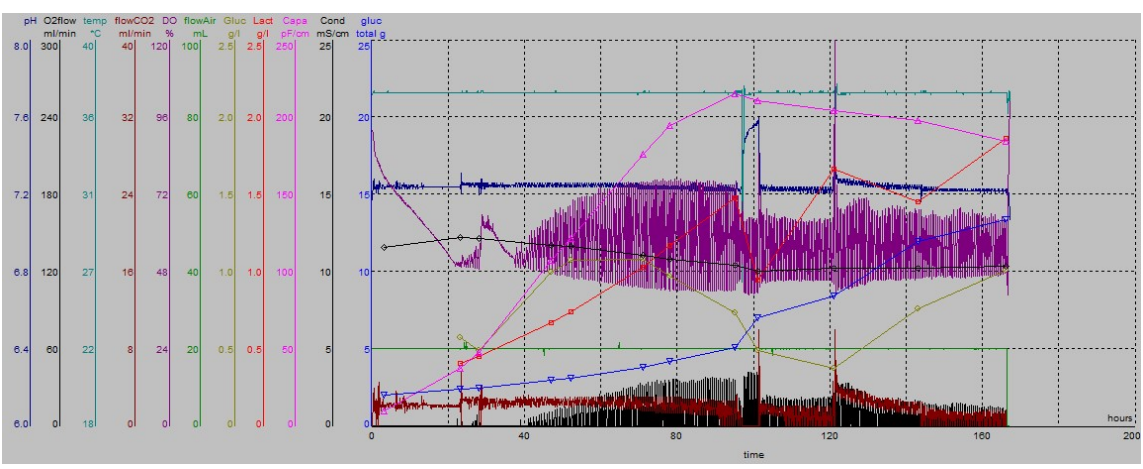

a

b

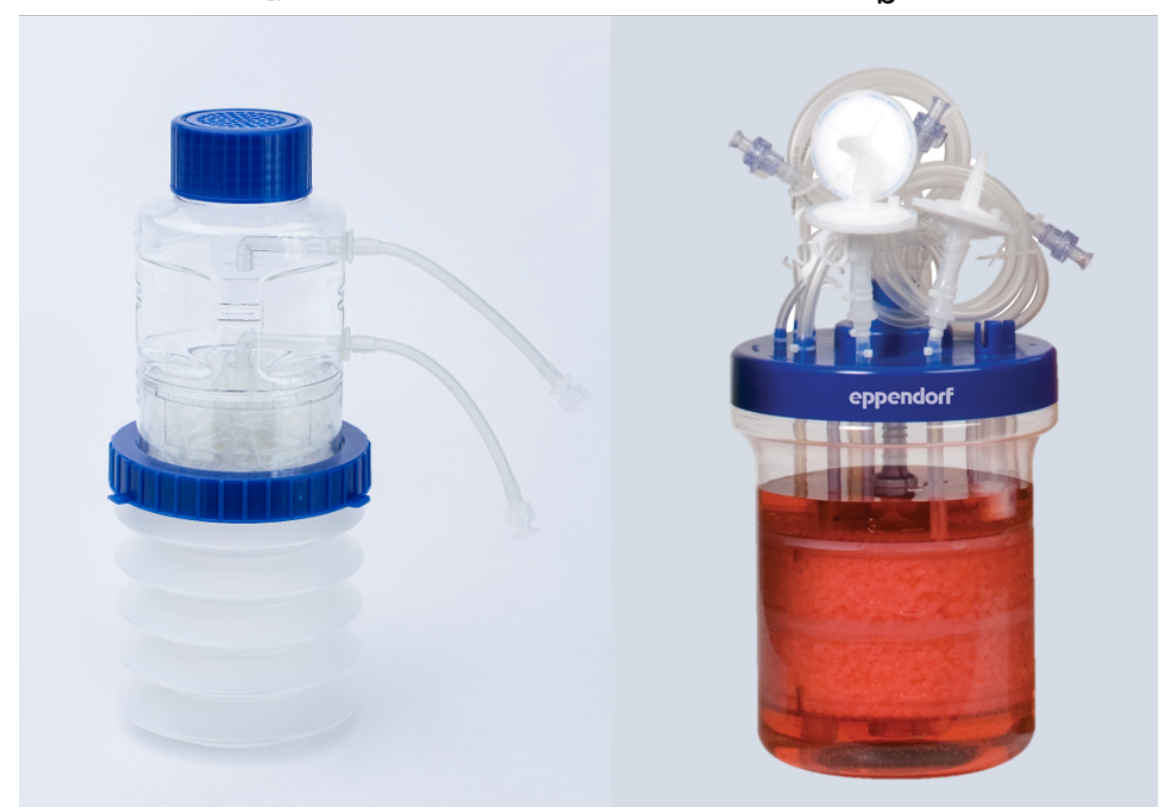

